\title{
AN EXAMINATION OF THE EFFECTS OF MECHANI- CAL SHOCKS AND VIBRATIONS UPON THE RATE OF DEVELOPMENT OF FERTILIZED EGGS
}

BY

\section{DAVID D. WHITNEY}

It has been shown in recent years by several investigators that mechanical shocks and vibrations may start the development of unfertilized eggs of certain animals. ${ }^{1}$ It has also been stated by Meltzer $^{2}$ that the early development of fertilized eggs of the sea urchin is greatly accelerated when the eggs are subjected to mechanical shocks and vibrations. Furthermore, Mathews and Whitcher ${ }^{3}$ believe they have obtained results which show that such influences may cause the embryos of the sea urchin to be either larger or smaller than those of the control eggs, or abnormal in shape, or to develop more slowly than normal eggs.

Assuming these results to be well founded, I undertook, during the summer of 1905, some experiments to determine the influence of shaking at different stages of development. In order to exclude the obvious possibility, that the results of Meltzer, and perhaps those of Mathews and Whitcher, were due to differences in temperature, care was taken to make this factor the same in the shaken eggs and in the control. In some cases this was done by means of a water jacket a round both sets of eggs. It soon became apparent that no difference at all in the rate occurred when this precaution was carried out; so that the work resolved itself into testing the claims of these investigators respecting the influence of shock on the early stages of development.

At the suggestion and under the kindly supervision of Prof.

${ }^{1}$ Mathews: Amer. Jour. Physiol., I901, vi, p. 142. Fisher: Amer. Jour. Physiol., 1902, vii, p. 301.

${ }^{2}$ Meltzer: Amer. Jour. Physiol, 1903, ix, p. 245.

${ }^{3}$ Mathews and Whitcher: Amer. Jour. Physiol., I903, viii, p. 301.

Journal of Experimental Zoölogy, Vol. iII, No. I. 
T. H. Morgan, I have studied the influence of mechanical agitation and vibration upon the fertilized eggs of Arbacia, Asterias, Fundulus heteroclitus and Ctenolabrus.

Of the fertilized eggs of Arbacia twenty-five lots from six individuals were shaken from one to forty-five minutes. Some were shaken by hand and others by means of a small hot-air engine. The eggs were placed in a test-tube half full of sea water, which in some cases contained small pebbles about the size of an ordinary pin head; in other cases water alone was present. The tube was then shaken back and forth one hundred to three hundred times per minute.

Six other lots from two other individuals were placed in a thick walled test-tube which swung vertically, and, by the use of the small engine, the bottom of the tube was made to strike quite hard against the side of a board from one hundred and fifty to four hundred times a minute.

In all cases the temperature of the control was the same as that of the shaken eggs. When the engine was employed for shaking, the test-tube was kept under running sea water, but when shaken by hand it was wrapped up in wet cloths. The eggs of the controls were also kept under similar conditions. When taken from the test-tube, the eggs were all kept at room temperature, $23^{\circ}-26^{\circ} \mathrm{C}$. Thus the temperature of the shaken and non-shaken eggs was always exactly the same.

After fertilization, the eggs were usually allowed to stand three to five minutes before using. In some cases, however, they were shaken immediately after fertilization. In other cases they were allowed to stand from five to twenty-five minutes.

In all these thirty-one sets of shaken eggs from eight individuals no acceleration of cleavage was noted in the earlier stages, nor were the plutei ever larger than those of the controls. In many cases the majority of the embryos of the shaken eggs were small and abnormal in shape, and were swimming upon the bottom of the dish, thus corroborating some of Mathews' and Whitcher's observations. This was especially true if the eggs were shaken in the test-tube with the small pebbles. Usually a few large plutei were found in both the controls and the shaken lots; but in no one 
of these lots did there seem to be more large plutei than in the other.

The following experiments will illustrate the general character of the results obtained from Arbacia:

Experiment I. Fuly II.-Temperature of sea water $23^{\circ} \mathrm{C}$.; of room $25^{\circ} \mathrm{C}$. All lots of eggs, after fertilization, were kept at $23^{\circ}$ C. for forty-five minutes, and were then placed in finger bowls of water at room temperature.

Lot A. Control. Great care taken in handling the eggs so as to prevent any jarring or shaking.

Lot B. Three minutes after fertilization the eggs were placed in a test-tube the bottom of which struck for forty-five minutes against the side of a wooden box two hundred and seventy-five to three hundred and fifty times a minute.

Lot C. Ten minutes after fertilization. Shaken five minutes back and forth two hundred and fifty times a minute in a test-tube half full of water plus some small pebbles.

Lot D. Immediately after fertilization. Shaken five minutes in same manner as lot $\mathrm{C}$.

The early stages and the plutei of lots B, C and D were like those of the control.

Experiment II. Fuly $r x$. - Conditions and results the same as in I.

Experiment III. Fuly I2.-Temperature the same as in $I$ and $I I$.

Lot A. Control.

Lot B. Shaken thirty minutes back and forth two hundred and forty times per minute, in a test-tube half full of water. The tube was in a jacket of running water.

Early cleavages and the plutei of B were the same as A.

Experiment VI. Fuly I3.-Temperature of sea water $23^{\circ} \mathrm{C}$.; of room $26^{\circ} \mathrm{C}$.

Lot A. Control.

Lot B. Shaken five minutes back and forth two hundred times a minute in test-tube half full of water plus some small pebbles.

Lot C. Shaken one minute back and forth three hundred times per minute in same manner as $B$. 
Early segmentation of all three lots the same.

Fuly I6.--Lot A. Normal plutei swimming through water in the dish.

Lot B. Normal plutei swimming upon the bottom of the dish.

Lot C. Normal plutei. A few swimming through the water, and the remainder swimming upon the bottom of the dish.

Experiment VIII. Fuly I3.--Lot A. Control.

Lot B. Shaken three minutes by hand back and forth three hundred times per minute in a small vial half full of water plus small pebbles.

Lot C. Shaken five minutes in same manner as B.

$\mathrm{B}$ and $\mathrm{C}$ were one-half hour later than $\mathrm{A}$ in showing the first cleavage.

Fuly I7.-Lot A. Normal plutei swimming through water in a dish.

Lot B. Very few normal plutei. Mostly gastrulæ, and many of them abnormal. Both plutei and gastrulæ were swimming upon the bottom of the dish.

Lot C. Normal and abnormal plutei swimming upon bottom of dish.

Experiment XII. Fuly I7.-The sea urchins were kept in an ice chest at a temperature of $9^{\circ} \mathrm{C}$. from five to six hours. Then the ovaries were quickly removed to water at $9^{\circ} \mathrm{C}$. and fertilized by the sperm that had been shed by the males while in the ice chest.

Lot A. Control at $9^{\circ} \mathrm{C}$. for thirty minutes.

Lot B. Shaken thirty minutes back and forth two hundred and ten times per minute, in a test-tube half full of water. The tube was in an ice water bath at $3^{\circ} \mathrm{C}$.

Lot C. Shaken one minute back and forth three hundred times, at a temperature of $1 \mathrm{I}^{\circ} \mathrm{C}$. They were allowed to remain at this temperature for thirty minutes. At the expiration of this time, the three lots were placed in room temperature of $25^{\circ}$ to $26^{\circ} \mathrm{C}$.

The early segmentation and normal plutei of the three lots appeared at the same time respectively.

Some eggs were placed at room temperature $-25^{\circ}$ to $26^{\circ} \mathrm{C}$. 
and others from the same lot were put under running sea water at a temperature of $23^{\circ} \mathrm{C}$. The eggs at room temperature developed in the early segmentation one stage in advance of those which were under running water.

In all the experiments great care was taken in handling the control eggs, both before and after fertilization, so as to prevent jarring which might influence the rate of development of the control eggs in such a way that it would be identical with the eggs intentionally shaken.

Meltzer shook the eggs of Arbacia by hand and also by means of the piston of a stationary engine. $\mathrm{He}$ also placed them in dishes on the vibrating part of the same engine. He does not state whether the eggs of the control were kept at the same temperature as those that were being shaken, but only states that the temperature of the room was slightly higher than the outside temperature. I have made careful records of the temperature of the places in the engine house where he performed his experiments. If the conditions then were the same as they are now, all his results can be explained by the different degrees of temperature to which the eggs were subjected.

The eggs that he shook by hand in small vials containing small glass beads developed faster. The temperature in such a case would be increased by the friction of the beads and water, and by the warmth of the hand, in a remarkably short space of time.

I found that the temperature in the test-tube which struck against a board, when not kept under running water, was raised two to four degrees if the experiment was continued for fifteen to twenty minutes.

Meltzer may have avoided all these difficulties and have kept all the eggs of a series at the same temperature, but he does not state this; and from what he does say, he seems to have paid little attention to temperature and consequently concluded that the acceleration of development which he obtained was due to vibration and shaking. I find on the contrary, that by keeping all the eggs of a series at the same temperature no acceleration of development can be obtained by subjecting them to a slight or even to a great amount of mechanical agitation or vibration. 
Fèrtilized eggs of Asterias subjected to mechanical shocks gave only negative results. About thirty-five lots from twelve individuals were used. The apparatus employed for producing the shocks was a thick glass test-tube, the bottom of which struck against two boards from two hundred to three hundred and fifty times per minute- - the same that was used in connection with the eggs of Arbacia.

The eggs were kept in this tube, which was constantly in motion, from fifteen minutes to seven hours. Some were subjected to shock immediately after fertilization, and others remained undisturbed from five to thirty minutes before being placed in the tube. The temperature was kept uniform in all lots of eggs of the same experiment.

When many of the eggs had reached the eight-cell stage, about two hundred of them were selected at random, and the percentage of the eggs in the various segmentation stages was determined by counting. The shaken eggs usually varied from $\mathrm{I}$ to 3 per cent. either above or below the percentage of the same stages in the nonshaken lots. As the percentage varied so slightly, sometimes above and sometimes below that of the control, I concluded that the segmentation was neither hastened nor retarded by mechanical shocks.

The eggs of Fundulus heteroclitus were also placed in the testtube of this apparatus and subjected to slight and to severe shocks, from a few minutes to ten hours. About forty lots-from twenty to twenty-five individuals-were used. As the early development of these eggs was found to take place normally in a damp chamber, some of them were placed in a test-tube, the air of which was kept moist by a piece of wet filter paper, and subjected to shocks. Similar results were obtained from both methods.

A few lots were placed in a test-tube half filled with water and the tube was made to move back and forth in a horizontal position from two hundred to three hundred and fifty times per minute.

In none of these experiments did the early cleavage stages of the shaken eggs appear earlier than in those of the controls.

As the eggs of Ctenolabrus float upon the surface of the water, 
the test-tube was inverted, and its upper end made to strike against boards, as in the former experiments. In some of the experiments the tube struck against the boards gently, and in others it struck severely enough to kill many of the eggs. Intermediate shocks were also tried.

About thirty lots-from fifteen to twenty individuals-were used and were subjected to shocks from five minutes to several hours. In all these experiments the early cleavages appeared at the same time both in the controls and in the shaken eggs.

From the foregoing observations it appears that mechanical shocks and vibrations are not effective in accelerating the early segmentation of the fertilized eggs of Arbacia, Asterias, Fundulus and Ctenolabrus.

These observations were made at the Marine Biological Laboratory at Wood's Hole, while occupying one of the tables of the Carnegie Institution. 